\title{
Uveal Ganglioneuroma due to Germline PTEN Mutation (Cowden Syndrome) Presenting as Unilateral Infantile Glaucoma
}

\author{
Sarah W. DeParis ${ }^{a} \quad$ Michele Bloomer ${ }^{a}$ Ying Han $^{a} \quad$ M. Reza Vagefi ${ }^{a}$ \\ Joseph T.C. Shieh ${ }^{b}$ David A. Solomon ${ }^{c}$ James Grenert ${ }^{c}$ \\ Alejandra G. de Alba Campomanes ${ }^{a}$ \\ Departments of a Ophthalmology, ${ }^{b}$ Pediatrics and ${ }^{\mathrm{C} P a t h o l o g y, ~ U n i v e r s i t y ~ o f ~ C a l i f o r n i a, ~ S a n ~ F r a n c i s c o, ~ C A, ~ U S A ~}$
}

\section{Keywords}

Uveal ganglioneuroma $\cdot$ Cowden syndrome ·

PTEN mutation - Ocular oncology

\begin{abstract}
Purpose: Uveal ganglioneuroma is a rare tumor that usually occurs in association with neurofibromatosis type 1. Here, we present a rare case of a uveal ganglioneuroma leading to a diagnosis of the tumor predisposition condition Cowden syndrome. Procedures: A 5-year-old girl with unilateral refractory glaucoma secondary to diffuse iris and choroidal thickening developed a blind, painful eye. Enucleation was performed, and histopathology revealed infiltration of the entire uveal tract by neoplastic spindle cells containing admixed ganglion cells diagnostic of uveal ganglioneuroma. Targeted next-generation sequencing of 510 cancer-associated genes was performed on tumor tissue and peripheral blood. Results: A germline nonsense mutation in the PTEN gene was found, accompanied by loss of heterozygosity in the tumor. A diagnosis of Cowden syndrome was made, for which the family sought genetic counseling and initiated the recommended cancer screening. Conclusions: A novel association is found between uveal ganglioneuroma and Cowden syndrome, emphasizing the value of genetic tissue testing in managing patients with rare ocular tumors.
\end{abstract}

(c) 2016 S. Karger AG, Basel

\section{KARGER}

(c) 2016 S. Karger AG, Basel

E-Mail karger@karger.com

www.karger.com/oop

\section{Introduction}

Ganglioneuroma of the choroid is a rare tumor usually associated with neurofibromatosis type 1 (NF1), with only 9 cases previously reported [1-10]. Cowden syndrome is caused by a germline mutation in the PTEN tumor suppressor gene and is characterized by hamartomatous growths as well as an increased risk for breast, thyroid, endometrial, renal, and gastrointestinal cancer [11]. To our knowledge, no association between uveal ganglioneuroma and Cowden syndrome has been previously reported. Here, we describe an informative case of a uveal ganglioneuroma presenting as a unilateral infantile glaucoma leading to a diagnosis of Cowden syndrome via targeted next-generation sequencing.

\section{Methods}

Retrospective analysis of clinical, histopathologic, and genetic records of 1 patient was performed. Targeted next-generation sequencing of 510 cancer-associated genes was performed on genomic DNA isolated from peripheral blood and microdissected tumor tissue in the Clinical Cancer Genomics Laboratory at the University of California, San Francisco. A standard bioinformatics pipeline was used to assess for germline and somatic single-nucleotide variants, small insertions/deletions, structural variants, and copy number changes.
Alejandra G. de Alba Campomanes, MD, MPH

10 Koret Way

San Francisco, CA 94143 (USA)

E-Mail alejandra.dealba@ucsf.edu 
Fig. 1. Clinical findings. a External photograph of the right eye of the patient at presentation at 2 years of age, showing peripheral anterior synechiae with poor pupillary dilation and ectropion uveae. $\mathbf{b}$ B scan of the right eye 9 months after initial presentation demonstrates a shallow serous retinal detachment and diffuse choroidal thickening. c T1-weighted MRI of the same patient at 2 years of age, showing enlargement of the right globe and smooth, diffuse thickening of the choroid.
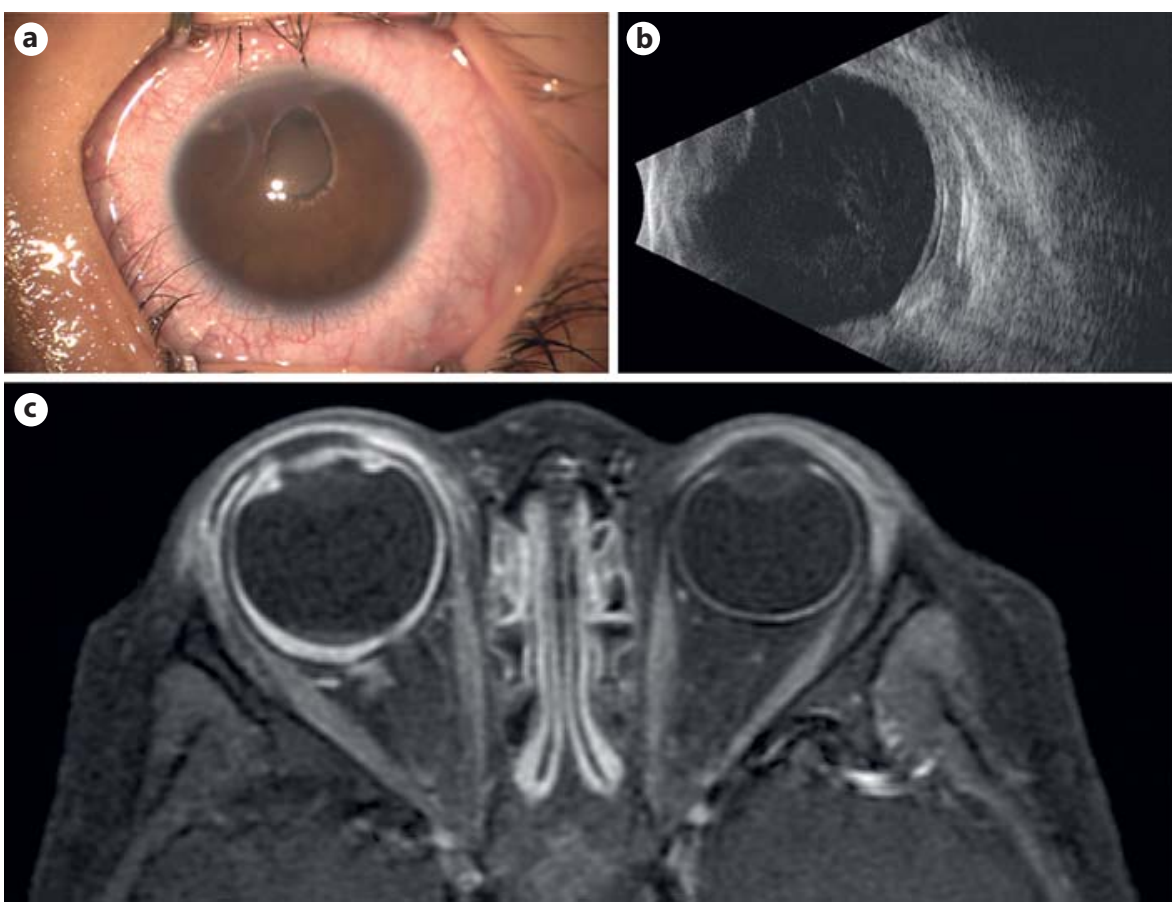

\section{Results}

A 2-year-old girl born at 31 weeks with a history of macrocephaly, developmental delay, and gradual enlargement of the right eye presented with elevated intraocular pressure in the right eye. On initial examination under anesthesia, the intraocular pressure was $28 \mathrm{~mm} \mathrm{Hg}$ in the right eye and $19 \mathrm{~mm} \mathrm{Hg}$ in the left eye. The axial length was $26.0 \mathrm{~mm}$ in the right eye compared to $20.6 \mathrm{~mm}$ in the left eye. Examination of the anterior segment revealed a curvilinear opacity in the inferior cornea, peripheral anterior synechiae with poor pupillary dilation, and ectropion uveae in the right eye (Fig. 1a). Fundus examination revealed a dysplastic-appearing right optic nerve with a cup-to-disc ratio of 0.8 and rim thinning superiorly. Examination of the left eye was unremarkable. The patient's intraocular pressure remained uncontrolled despite maximal medical management, and an Ahmed valve was subsequently placed in the right eye 6 months after the initial presentation. The intraocular pressure in the right eye remained uncontrolled despite this, and multiple subsequent surgeries were performed over the following 2 years due to progressive iris thickening and pupillary membrane formation. B scan (Fig. 1b) and MRI (Fig. 1c) of the right eye showed a shallow serous retinal detachment and diffuse choroidal thickening. A small bi- opsy of the iris at the time of a pupilloplasty procedure revealed a spindle cell neoplasm with tumor cells that showed immunostaining for S-100, SOX-10, and GFAP (Fig. 2a-d) but not for HMB-45 and Melan-A (not shown). There were no morphologic features to suggest malignancy, with MIB-1 labeling present in approximately $2 \%$ of the tumor cells (Fig. $2 \mathrm{e}$ ).

The clinical presentation with a diffusely thickened uveal track, in conjunction with this small iris biopsy, suggested the possibility of neurofibroma. As such, the patient was subsequently referred for NF1 evaluation. The patient had 1 café-au-lait macula on the right buttock, but no other skin lesions or other stigmata of NF1. Her family history was negative for neurofibromatosis. Peripheral blood testing for NF1 was negative for pathogenic mutations, and chromosomal microarray analysis was unremarkable.

An additional pupilloplasty procedure was performed 6 months later, and an additional iris biopsy at that time showed the same spindle-shaped cells with small ovoid nuclei without prominent nucleoli or significant pleomorphism. The eosinophilic cytoplasm was slightly wavy. These cells did not show staining with HMB- 45 or smooth muscle actin (SMA) antibodies. They did stain positively for neurofilament and S-100 and were felt to be most consistent with a neurofibroma (Fig. 3). 


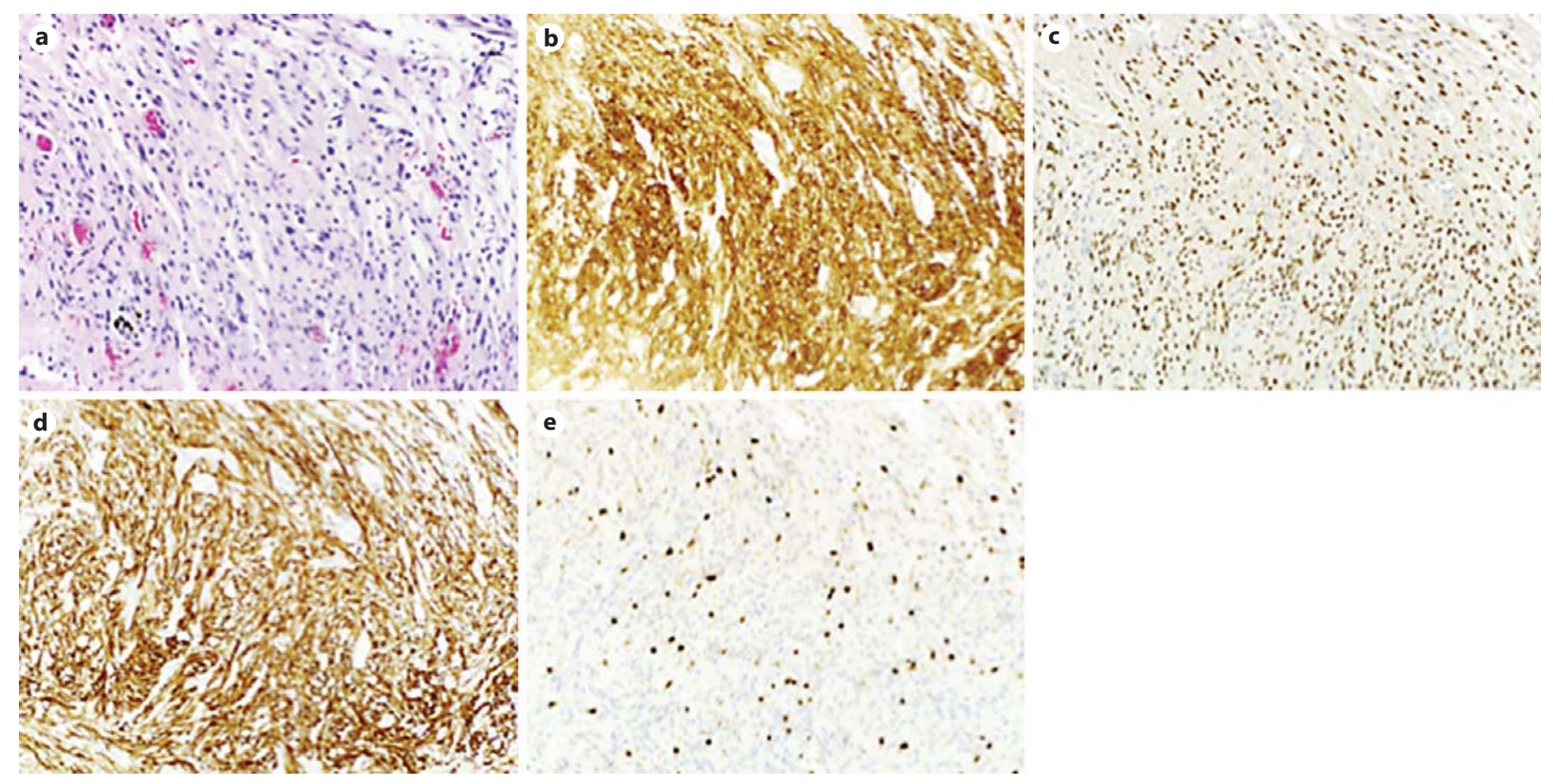

Fig. 2. Histopathology of the first iris biopsy. The iris biopsy was performed at the time of the pupilloplasty procedure 9 months after initial presentation. a Hematoxylin and eosin $(\times 200)$ revealed a spindle cell neoplasm with immunopositivity for S-100 (b), SOX-10 (c), and GFAP (d). e MIB-1 staining of the neoplasm, estimated at 2\% of the tumor cells.
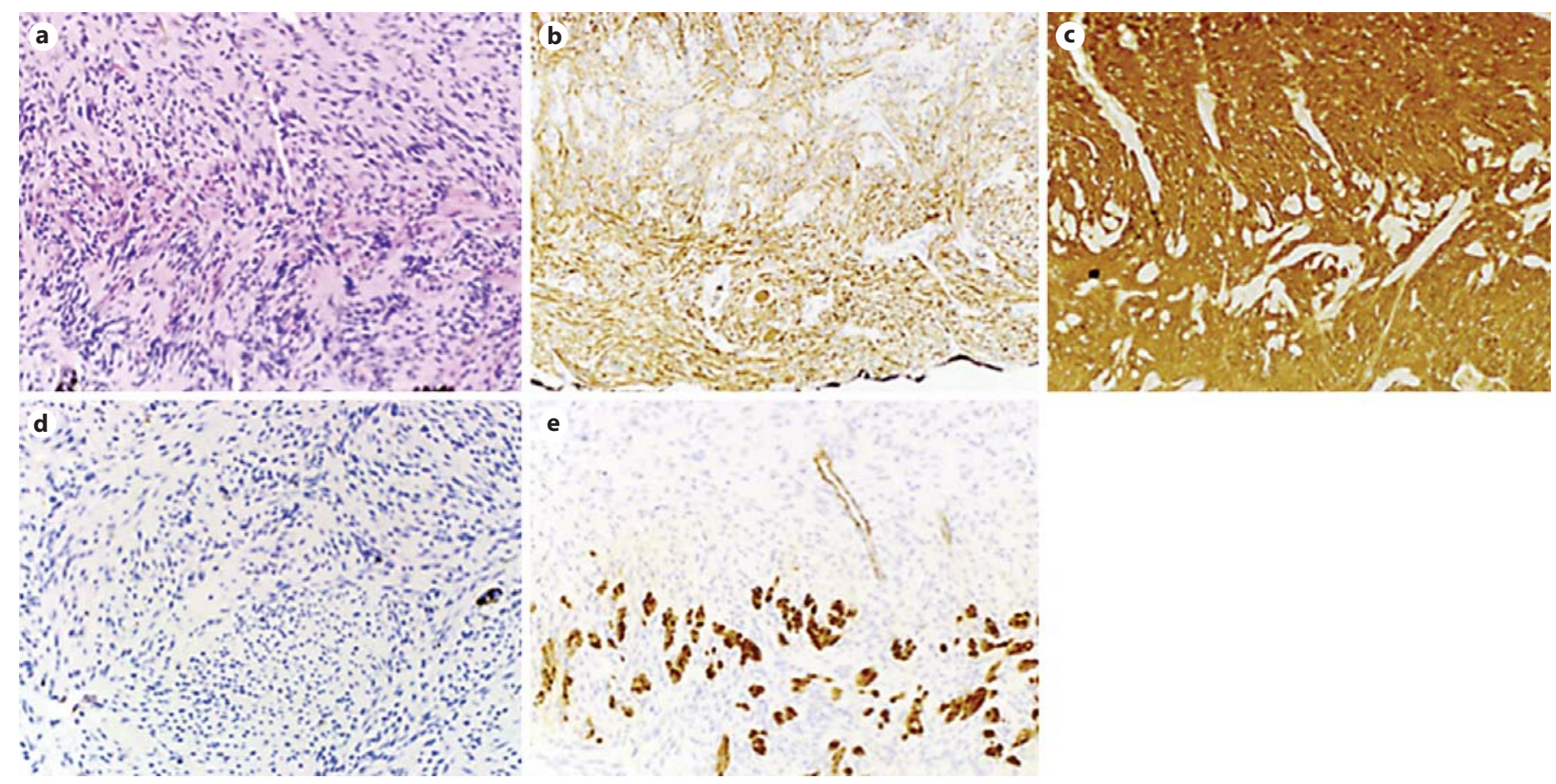

Fig. 3. Histopathology of the second iris biopsy. Fourteen months after initial presentation, an additional iris biopsy was performed at the time of a subsequent pupilloplasty procedure. a Hematoxylin and eosin $(\times 200)$ shows the same spindle-shaped cells as the first iris biopsy. The spindle cells demonstrate immunostaining for neurofilament (b) and S-100 (c). Immunohistochemical stains for HMB-45 (d) and SMA (e) were negative. 
Fig. 4. Gross pathology of the enucleated specimen. Enucleation of the patient's right eye was performed at 5 years of age. Gross photographs show a buphthalmic globe with an attached glaucoma drainage device (a) and diffuse, irregular choroidal thickening (b).
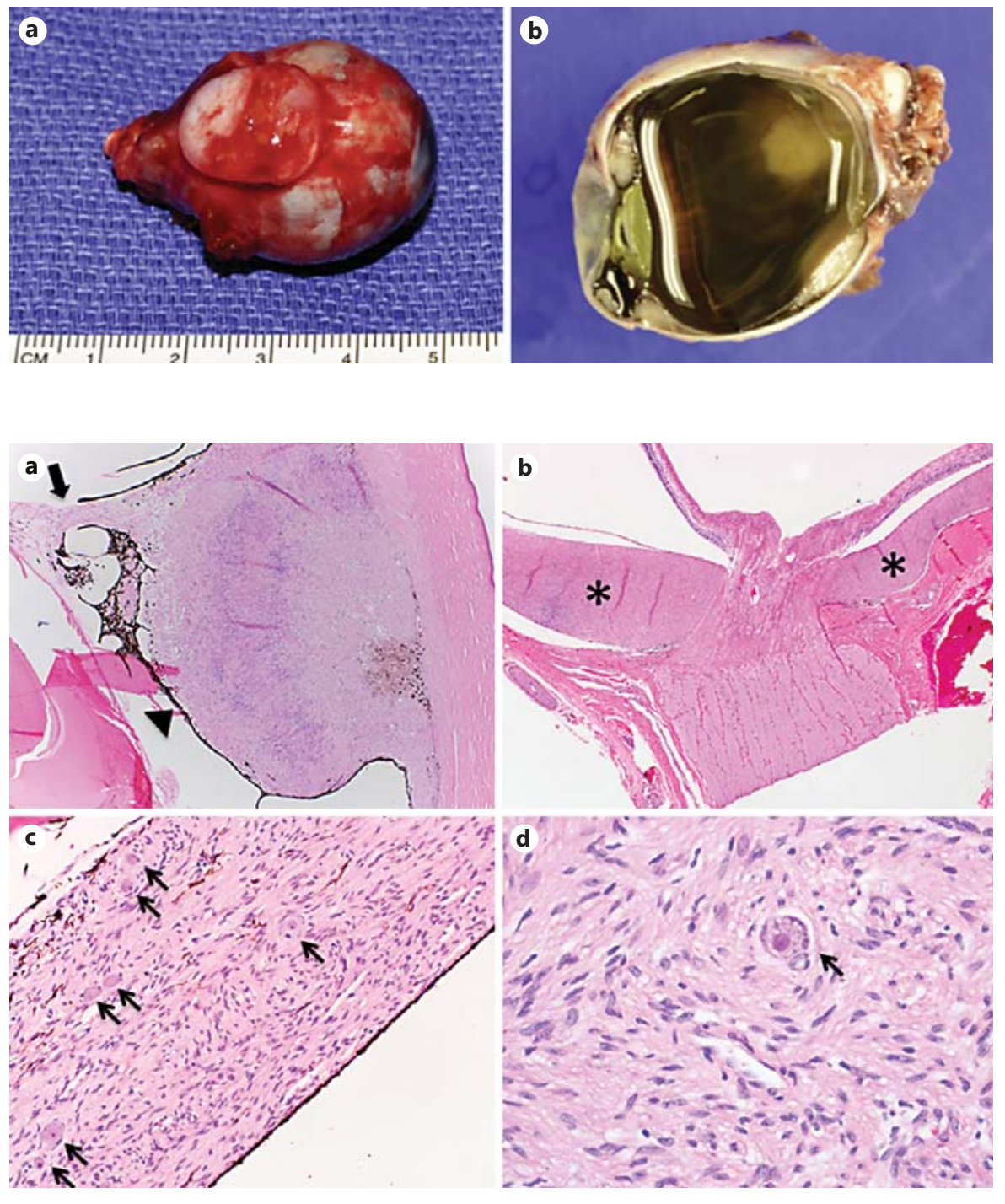

Fig. 5. Enucleation histopathology. Hematoxylin and eosin $(\times 20)$ shows diffuse uveal-tract infiltration by the spindle cell neoplasm including the iris (a, arrow) and ciliary body (arrowhead) and the choroid (b, asterisks). c Choroid magnification $(\times 100)$ demonstrating a dense infiltrate of spindle cells with multiple neoplastic ganglion cells of varying size (arrows). d Choroid magnification $(\times 400)$ showing a large dysmorphic ganglion cell (arrow).
At 5 years of age, the patient developed a blind, painful eye due to uncontrolled intraocular pressure, and the eye was enucleated (Fig. 4). On histopathology, the entire uveal tract including the iris, ciliary body, and choroid was infiltrated by neoplastic spindle cells with admixed large dysmorphic ganglion cells diagnostic of ganglioneuroma (Fig. 5). The neoplastic ganglion cells demonstrated immunopositivity for synaptophysin and neuronspecific enolase, while the Schwannian spindle cells showed immunopositivity for S-100 and SOX-10. MIB-1 showed a low proliferation index (Fig. 6). Antibodies against Melan-A, HMB-45, and SMA failed to stain the tumor cells. The long and short posterior ciliary nerves were enlarged, and the retina was detached by an eosinophilic exudate posteriorly. There were focal areas of full- thickness retinal atrophy. The sclera was thinned posteriorly, and the optic nerve was slightly atrophic.

Targeted next-generation sequencing of 510 cancerassociated genes was performed on genomic DNA isolated from the patient's peripheral blood and microdissected tumor tissue. This testing revealed a germline nonsense mutation in the PTEN gene (p.L146*) with copy number neutral loss of heterozygosity in the tumor. Additional somatic genomic alterations such as NF1 or RET mutations were not identified. A diagnosis of Cowden syndrome was established.

The patient was evaluated by the pediatric genetics service and is to undergo annual screening including yearly thyroid ultrasound and dermatologic examination, as well as neurologic, psychologic, and school evaluations. 

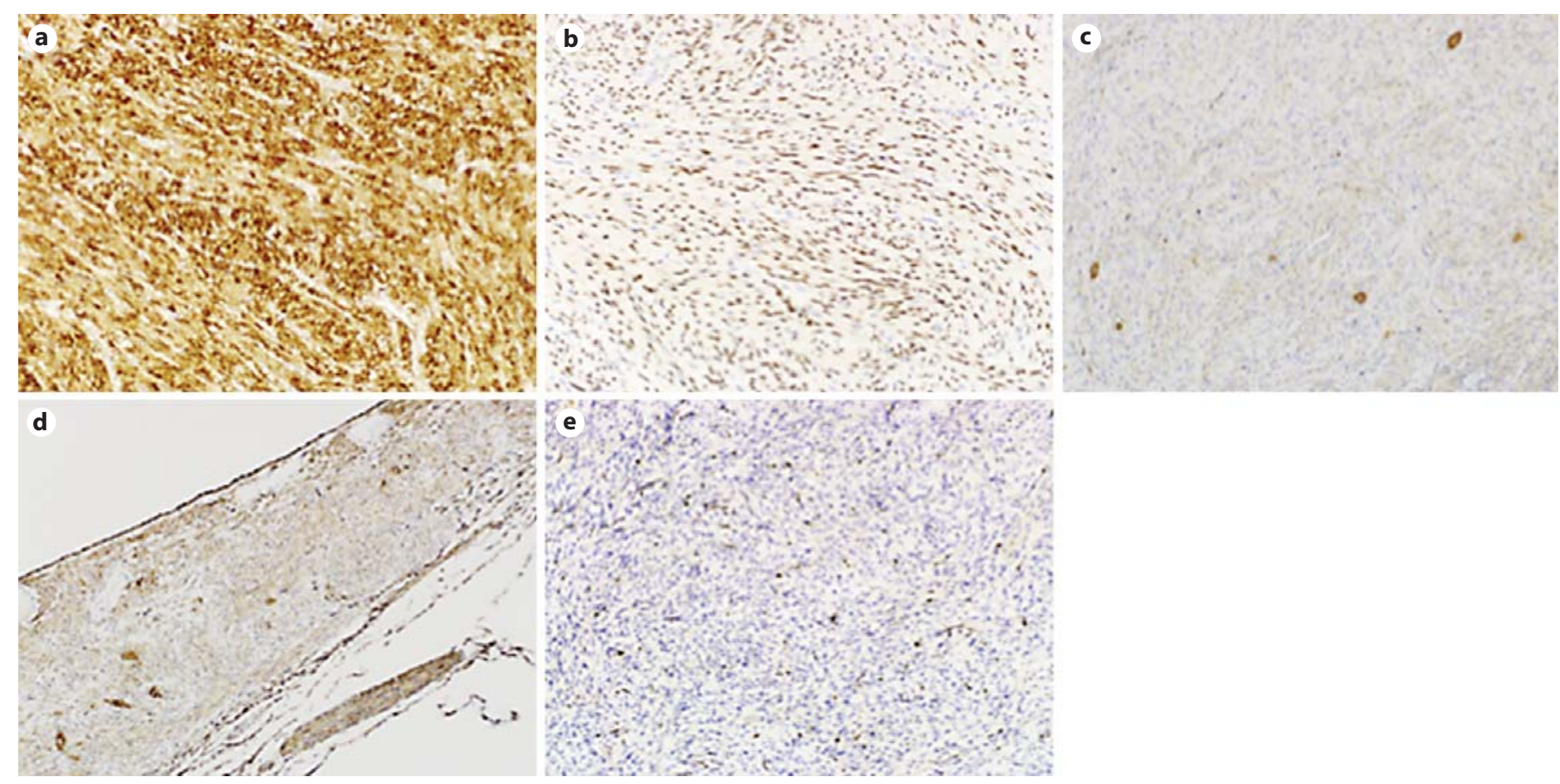

Fig. 6. Enucleation immunohistochemistry. The neoplastic spindle cells demonstrated immunostaining for S-100 (a) and Sox-10 (b), while the neoplastic ganglion cells demonstrated immunostaining for neuron-specific enolase (c) and synaptophysin (d), consistent with a diagnosis of ganglioneuroma. e MIB-1 labeling was present in less than $2 \%$ of the tumor cells.

A strong family history of early-onset uterine cancer was elicited in her maternal grandmother and multiple of her maternal grandmother's siblings. Genetic testing was also recommended for the patient's 2 siblings aged 4 and 7 , which is currently underway. Additionally, the patient was found to have an arteriovenous malformation in the left arm when she developed pain due to compartment syndrome, and she underwent surgical resection and fasciotomy.

\section{Discussion}

Ganglioneuroma is typically a benign, slow-growing tumor arising from neural crest cells that is most commonly found along the sympathetic chain in the posterior mediastinum, retroperitoneum, adrenal gland, and neck $[12,13]$. Ganglioneuroma of the uveal tract is an extremely rare entity. These tumors can present with buphthalmos, intractable glaucoma, or as a blind, painful eye [110]. On review of the literature, we found only 9 prior cases of uveal ganglioneuroma reported [1-10], 7 of which were in the setting of newly diagnosed or previ- ously established NF1 [1-8]. One case of choroidal ganglioneuroma without confirmed NF1 has been reported in the German literature [9], and 1 case was reported in the French literature of which details were not accessible [10].

The PTEN hamartoma tumor syndrome includes a continuum of disorders including Cowden syndrome, Bannayan-Riley-Ruvalcaba syndrome, and LhermitteDuclos disease, all caused by germline mutations in $P T E N$, a tumor suppressor gene [11]. The mutation is typically inherited in an autosomal dominant fashion, but in up to $44 \%$ of the cases, it occurs de novo with no prior family history [14]. Cowden syndrome is characterized by mucocutaneous findings including facial trichilemmomas, oral papillomas, mucocutaneous neuromas, and acral keratoses, but these are variable. Other features include vascular anomalies, lipomas, fibromas, benign thyroid nodules, gastrointestinal polyps, macrocephaly, and developmental delay $[11,15]$. Gastrointestinal ganglioneuromatous polyps have as well been reported in patients with Cowden syndrome [16]. Importantly, these patients carry an increased risk for breast, thyroid, endometrial, renal, and gastrointestinal cancer $[11,15]$. As 
such, enhanced cancer screening is recommended in these patients. For adults, the recommended regimen includes annual thyroid ultrasound and dermatologic examination beginning at the age of 18 , mammography beginning at the age of 30 , colonoscopy beginning at the age of 35 , and renal imaging beginning at the age of 40 [17].

Tan et al. [15] described the prevalence of clinical features of PTEN mutations in the pediatric population and noted macrocephaly in $100 \%$, autism or developmental delay in $82 \%$, dermatologic features in $60 \%$, vascular anomalies such as arteriovenous malformations or hemangiomas in $29 \%$, and gastrointestinal polyps in $14 \%$ of the patients. Thyroid cancer and germ cell tumors were also noted to be associated. Thus, screening with annual thyroid ultrasound and dermatologic examinations as well as psychiatric and school evaluations are indicated in children.

To our knowledge, this is the first reported case of a uveal ganglioneuroma in a patient with PTEN hamartoma tumor syndrome. This diagnosis was only possible through tumor genetic profiling, which allowed us to identify a germline mutation that confers an increased lifelong risk for systemic malignancy to its carriers. Our patient exhibited a number of the clinical features of PTEN syndrome including developmental delay, macrocephaly, and arteriovenous malformation, but no unifying diagnosis had been established prior to genetic testing of her uveal tumor. This diagnosis has broad implications for future health, as patients are to undergo enhanced cancer screening per the above guidelines. It also carries great significance for a family, as siblings and other family members should undergo genetic testing, and an affected patient's future offspring have a 50\% chance of inheriting the disease.

This case highlights how genomic profiling is revolutionizing cancer diagnostics. Combining histopathological evaluation and genetic evaluation should be considered in cases of diagnostic uncertainty. These tools may have particular use in rare tumors of the eye and elsewhere.

\section{Acknowledgements}

We would like to thank Boris Bastian, MD, PhD, Nancy Joseph, $\mathrm{MD}, \mathrm{PhD}$, and Iwei Yeh, $\mathrm{MD}, \mathrm{PhD}$, for their work in establishing and validating the UCSF500 Cancer Gene Panel.

\section{Statement of Ethics}

Genetic testing was performed with written parental informed consent. The study adhered to the requirements for human research protection by the institution's review board.

\section{Disclosure Statement}

None of the authors have any financial interests to disclose. No conflicting relationship exists for any author.

\section{References}

1 Woog JJ, Albert DM, Craft J, Silberman N, Horns D: Choroidal ganglioneuroma in neurofibromatosis. Graefes Arch Clin Exp Ophthalmol 1983;220:25-31.

2 Shome D, Vemuganti GK, Honavar SG: Choroidal ganglioneuroma in a patient with neurofibromatosis type 1: a case report. Eye (Lond) 2006;20:1450-1451.

3 Ishijima K, Kase S, Noda M, Ishida S: Intraocular neovascularization associated with choroidal ganglioneuroma in neurofibromatosis type 1. Eur J Ophthalmol 2011;21:837840.

4 Goyal S, Park A, Zeglam A, Brown H, Pemberton JD: Choroidal ganglioneuroma and orbital plexiform neurofibroma presenting as buphthalmos in an infant with neurofibromatosis type 1. Ophthal Plast Reconstr Surg 2016;32:e87-e89.
5 Ozgun G, Adim SB, Ugras N, Yazici B: Cooccurrence of choroidal pigmented ganglioneuroma and plexiform neurofibroma in a patient with neurofibromatosis 1 . Kaohsiung J Med Sci 2014;30:215-216.

6 Yazici B, Ozgun G, Adim SB: Choroidal ganglioneuroma in a patient with orbitopalpebral neurofibromatosis. Ophthal Plast Reconstr Surg 2014;30:e140-e142.

7 Plamondon M, Auger C: Melanic ganglioneuroma of the ocular choroid in Recklinghausen's disease. Union Med Can 1953;82:13681373 .

8 Mbagwu M, Rahmani B, Srivastava A, Burrowes D, Bryar PJ: Unsuspected ganglioneuroma of the choroid diagnosed after enucleation. Ocul Oncol Pathol 2015;2:48-50.

9 Kroll P, Busse H, Bergmann M: Choroid ganglioneuroma in childhood. Klin Monbl Augenheilkd 1992;201:185-187.
10 Francois J, Hanssens M, Evens L: Melanic ganglioneuroma of the choroid. Bull Soc Belge Ophtalmol 1972;162:858-867.

11 Pilarski R, Burt R, Kohlman W, Pho L, Shannon KM, Swisher E: Cowden syndrome and the PTEN hamartoma tumor syndrome: systematic review and revised diagnostic criteria. J Natl Cancer Inst 2013;105:1607-1616.

12 Okamatsu C, London WB, Naranjo A, Hogarty MD, Gastier-Foster JM, Look AT, LaQuaglia M, Maris JM, Cohn SL, Matthay KK, Seeger RC, Saji T, Shimada H: Clinicopathological characteristics of ganglioneuroma and ganglioneuroblastoma: a report from the CCG and COG. Pediatr Blood Cancer 2009;53:563-569. 
13 Bacci C, Sestini R, Ammannati F, Bianchini E, Palladino T, Carella M, Melchionda S, Zelante L, Papi L: Multiple spinal ganglioneuromas in a patient harboring a pathogenic NF1 mutation. Clin Genet 2010;77:293-297.

14 Mester J, Eng C: Estimate of de novo mutation frequency in probands with PTEN hamartoma tumor syndrome. Genet Med 2012;14: 819-822.
15 Tan MH, Mester J, Peterson C, Yang Y, Chen JL, Rybicki LA, Milas K, Pederson H, Remzi B, Orloff MS, Eng C: A clinical scoring system for selection of patients for PTEN testing is proposed on the basis of a prospective study of 3,042 probands. Am J Hum Genet 2011;88: $42-56$.

16 Stanich PP, Pilarski R, Rock J, Frankel WL, El-Dika S, Meyer MM: Colonic manifestations of PTEN hamartoma tumor syndrome: case series and systematic review. World J Gastroenterol 2014;20:1833-1838.
17 Daly MB, Pilarski R, Axilbund JE, Buys SS, Crawford B, Friedman S, Garber JE, Horton C, Kaklamani V, Klein C, Kohlmann W, Kurian A, Litton J, Madlensky L, Marcom PK, Merajver SD, Offit K, Pal T, Pasche B, Reiser G, Shannon KM, Swisher E, Voian NC, Weitzel JN, Whelan A, Wiesner GL, Dwyer MA, Kumar R: Genetic/familial high-risk assessment: breast and ovarian, version 1.2014. J Natl Compr Canc Netw 2014;12:1326-1338. 